\title{
Revision and Application of Questionnaire on Leadership Behaviors of PE Teachers in Higher Education Institutions
}

\author{
Bowen Wang ${ }^{1, \text { a }}$ \\ ${ }^{1}$ School of Physical Education and Health, Hainan Tropical Ocean University, Sanya, \\ Hainan Province, China \\ awbw1980@163.com
}

Key words: college physical education teachers; teacher leadership behavior; reliability; validity

\begin{abstract}
Teacher leadership behaviors are important in improving teaching qualities and promoting talent training levels. By using methods of literature analysis, in-depth interview and semi-open questionnaire, this paper identifies the leadership behaviors of college PE teachers into 3 categories: teamwork, system construction and professional development. Taking $324 \mathrm{PE}$ teachers from 7 colleges and universities as research objects, this paper carried out the survey on college teacher leadership behaviors. The results show that the coefficients of each category were 0.950 , 0.936 and 0.934 respectively. The $a$ coefficient of the whole questionnaire was about 0.945 . Comparative fitness indexes of the structural model $\chi^{2} / d f$, NFI, NNFI, IFI and CFI were 1.909, 0.91, 0.93, 0.94 and 0.94, showing the structural model had good goodness of fit. In addition, there were significant differences in leadership behaviors of college PE teachers with different ages, academic qualifications and titles. Teachers with higher education and titles had significantly higher performances than teachers with lower education and titles in 3 dimensions $(<0.01)$; older teachers had significantly higher performances than young teachers in the categories of system construction and professional development $(<0.01)$, while the difference in teamwork is not statistically significant $(>0.05)$. The leadership behavior questionnaire of college PE teachers can be used as an effective tool to monitor and evaluate the leadership behaviors of PE teachers.
\end{abstract}

\section{Introduction}

In recent years, higher education quality drops due to expansion of undergraduate enrollment. People's Daily once commented that, "the academic level of today's doctor is not good as the master 5 years ago, while the academic level of master 5 years ago is not good as the undergraduate student 10 years ago." China News also criticized the decline of college teaching quality as "indisputable fact" in the article Massive Students Dilute the Teaching Quality of Teachers; College Teaching Quality Become an Object of Public Denunciation. Teachers are the main force that affects the students. Teachers' behaviors, attitudes, knowledge and life styles influence students directly or indirectly through explicit and implicit courses, as well as students' observation and study process [1]. In order to improve the teaching quality of colleges and universities, we must attach importance to the development of teachers, and strengthen the training of teachers. Teachers should strengthen their study skills, broaden their horizons, update their knowledge, and constantly improve their professional abilities and the levels of education and teaching [2]. At present, domestic and foreign scholars have done many researches on the development of teachers. Most of these researches shown, teacher leadership can give a strong impetus to the development of teachers and help them to build positive attitudes towards life. Teacher leadership is the starting point of school cultural changes, and an effective strategy of teacher development [3]. PE teachers are important in college teacher system. They not only affect the development and training level of PE students, but also affect the physical and mental health of students from other majors. Therefore, enhancing the 
leadership ability of PE teachers is a key factor in the improvement of teaching qualities of colleges and universities. Of course, to enhance the leadership of teachers, we must conduct a scientific survey firstly, in order to grasp the current situation of leadership behaviors of PE teachers. Based on above analysis, it is of great theoretical and practical significance to revise the questionnaire which is suitable for college physical education teachers.

According to existing research results, Teacher Leadership is defined as following. "Teacher Leadership is a kind of collective, professional and multi-interactive leadership; its main purpose is to improve the teaching and learning effects." [4] The research on connotation and structure of teacher leadership started abroad in 1980s. In twenty-first century, scholars pointed out that the new era of teacher leadership has begun[5]. Many scholars have conducted fruitful research on this issue. Hart[6] (1995) tried to summarize the three kinds of teacher leadership behavior: guiding young teachers, occupation development and participation in school management. Leithwood and Duke[7] (1999) classified teachers' leadership behaviors into 6 directions, namely teaching leadership, transformational leadership, moral leadership, participation leadership, management leadership and leadership to changes. Katzenmeyer and his colleagues [8] (2007) divided teacher leadership behavior into the following three aspects: the leader of students and other teachers, the leader of daily affairs, and the leader in decision-making and cooperation processes. Danielson C.[9] (2008) put forward to three aspects of teacher's leadership behavior: school policies and projects, teaching and learning, communication and community relations. In China, researches of connotation and structure of teacher leadership are fewer. Scholars include Jian-sheng Jin, [1] (2007), Nai-gui Lu [10] (2006), Zheng Chen, Jun-wei Long, Pan Chen [11] (2010), Ai-jian Du [12] (2003) have studied the issue of teacher leadership structure. Through the analysis of above literature, it can be found that most studies are theoretical research, while quantitative researches on teacher leadership behavior, especially on teacher leadership behavior of physical education teachers, are rare to be seen. This paper tries to contribute on the empirical research of this issue. In this study, teacher leadership scale proposed by Kadir Beyciogluland Battal Aslan [13] (2010), as well as leadership behavior description questionnaire (LBDQ) proposed by Rody Rodriguez[14] (2013) served as the foundation, semi-open questionnaire and in-depth interview were also used to add survey items. In order to test its reliability and validity, the questionnaire was revised and improved to be suitable for Chinese college physical education teachers.

\section{Revision of the Questionnaire}

Research object. 112 college teachers who were engaged in physical education were chosen as the research object in the pretest. In the formal test, 351 physical education teachers were randomly selected from 7 colleges and universities, and a total of 324 valid questionnaires were collected (valid return rate was 92.3\%). Among them, 187 were male teachers, accounting for $57.7 \%$; 137 were female teachers, accounting for 42.3\%. 134 teachers were younger than 29 years old, accounting for $41.4 \%$; 105 were between $30-39$ years old, accounting for 32.4\%; 46 were between 40-49 years old, accounting for 14.2\%; 39 were between 50-59 years old, accounting for $12 \%$. For professional titles, 89 teachers had junior titles, accounting for $27.5 \%$; 177 people had medium-grade titles, accounting for 54.6\%; 58 people had senior titles, accounting for $17.9 \%$. For the aspect of educational degree, 195 teachers were undergraduate, accounting for $60.2 \% ; 87$ teachers were masters, accounting for 26.8\%; 42 people had doctoral degrees, accounting for 13\%.

Preparation of the questionnaire. The questionnaire used in this study was a self-edit questionnaire named Questionnaire of Leadership Behaviors of College Physical Education Teachers. The preparation of questionnaire included following steps.

First, the author studied a large number of literature on teacher leadership, reference to Teacher Leadership Scale proposed by Kadir Beyciogluland Battal Aslan [13] (2010), Leadership Behavior Description Questionnaire (LBDQ) proposed by Rody Rodriguez[14], and relevant information on 
teacher leadership behavior proposed by domestic scholars.

Second, a semi-open questionnaire survey and an in-depth interview were conducted. On the basis of above theory, the descriptions of leadership behavior of physical education teachers were collected, then related words were numbered and used to revise specific items of the questionnaire.

Third, the initial questionnaire was evaluated and modified. Experts, scholars and teachers were asked to evaluate items in the initial questionnaire, and evaluated the reflection degree of item content, as well as the scientificity and acceptability of the questionnaire. According to evaluation results, the questionnaire items were modified.

Fourth, pre-test. 112 teachers who were engaged in physical education teaching in colleges and universities were selected as objects. Then relevant data were statistically analyzed, including the re-scoring of reverse scoring items, calculation of total scores of each item, sorting, elimination of extreme data and other steps. The item analysis and exploratory factor analysis were used to make the questionnaire correspond to the theoretical framework.

Fifth, formal testing. 324 physical education teachers from 7 universities and colleges were selected as research objects. The results of the test were analyzed and used to test the reliability and validity of the questionnaire, including the total correlation, internal consistency, test-retest reliability, content and construct validity test.

Statistical processing. Statistical analysis and data processing were performed by using SPSS 17 and LISREL8.7. SPSS 17 was used for item analysis, exploratory factor analysis, test-retest reliability test and internal consistency reliability test. The confirmatory factor analysis of structural validity was performed by LISREL8.7, while the differences of leadership behavior from teachers with different ages, educational backgrounds and professional titles were analyzed by one-way Anova.

\section{Research Results}

Predict result. Project analysis. The correlations of each item and the total score were calculated. If the correlation coefficient was less than 0.40 , the item would be eliminated (V6, V10, V12, V13, V17, V19, V22, V24, V25). Correlations of remaining entries are between 0.636 and 0.852 . An independent sample $t$ test on high and low score groups was carried out with the boundary of $27 \%$ questionnaire scores. The operation steps went as the following. Total scores of each item were calculated, sorting down scores; points which were higher and lower than $27 \%$ were recorded, and generated new variables. Then the independent sample $t$ test was carried out, if the critical ratio of items did not reach the significant level, the item would be eliminated (V18, V29). Total 11 items were deleted, and 18 items remained at last (Table 1). 
Table 1.18 items of the questionnaire

No. Item Contents

V1 I am always ready to help new teachers and intern teachers.

V2 I am always willing to share my experience and experience with my colleagues.

V3 When I get the latest information, I always tell my colleagues in time.

V4 I always ask for my colleagues when I encounter difficulties in work and training.

V5 I would like to develop together with my colleagues in teaching and working.

V7 When I am in trouble, I always look for my colleagues.

V8 I am willing to work with colleagues and complete tasks of teaching and training.

V9 I am always passionate about activities with my colleagues.

V11 I would like to take part in setting school development goals and making strategic plans.

V14 I am willing to make teaching plans and teaching objectives.

V15 I am willing to actively participate in the development of school.

V16 I am willing to fulfill the responsibilities at work and training.

V20 When I come across something which violates the work principles, I am always against it.

V21 I also actively support students' academic activities outside the school.

V23 In teaching and training practice, I always improve my professional level according to the requirements of students.

V26 I always take a constructive approach to the development of this major.

V27 I always improve my teaching and training level according to the latest development of this major.

V28 I pay high attention to the development of this major.

Exploratory factor analysis. KMO test and Bartlett sphericity test were carried out for the data of the 18 items. The results showed that the KMO value was 0.877 , and the $\mathrm{P}$ value of Bartlett sphericity test was less than 0.001 . The data were suitable for factor analysis. Exploratory factor analysis was made by principal component method, using the maximum variance method to rotate factors, extracting common factor which were greater than 1, and getting 3 common factors finally. The contribution rate of explained variance was $77.67 \%$. After the rotation, the load of each factor was more than 0.4 , so there was no need to delete any items (detailed results can be seen in table 2 and table 3). According to the internal logic connection of each item and related concepts, the 3 common factors were named as team cooperation factor, system construction factor and professional development factor. 
Table 2 Factor load after rotation

\begin{tabular}{llll}
\hline item & Factor 1 & Factor 2 & Factor 3 \\
\hline V1 & 0.787 & & \\
V2 & 0.823 & & \\
V3 & 0.845 & & \\
V4 & 0.862 & & \\
V5 & 0.779 & & \\
V7 & 0.838 & & \\
V8 & 0.759 & & \\
V9 & 0.741 & & \\
V11 & & 0.763 & \\
V14 & & 0.873 & \\
V15 & & 0.836 & \\
V16 & & 0.864 & \\
V20 & & 0.840 & 0.848 \\
V21 & & 0.804 & 0.879 \\
V23 & & & 0.844 \\
V26 & & & \\
V27 & & & \\
V28 & & & \\
\hline
\end{tabular}

Table 3 Eigenvalue, variance contribution rate and cumulative variance contribution rate

\begin{tabular}{lrcc} 
& eigenvalue & variance contribution rate & Cumulative variance contribution rate \\
\hline factor1 & 5.731 & 31.839 & 31.839 \\
factor 2 & 4.715 & 26.196 & 58.035 \\
factor 3 & 3.534 & 19.631 & 77.666 \\
\hline
\end{tabular}

Survey results. reliability analysis. Retest of reliability. $10 \%$ investigators were randomly selected and measured again after a week, the correlation coefficient of results in two times were calculated as retest reliability coefficient. According to related data, the correlation coefficient was $\mathrm{r}=0.871$, which shows the good stability of measurement results. Hence, the data was reliable.

Internal consistency reliability test. The consistency coefficient proposed by Cronbach was used as internal consistency reliability index in the questionnaire, total scores and $a$ coefficient of the questionnaire were calculated by SPSS17.0 software (Table 4). From the results, we can see that the internal consistency reliability of the Questionnaire of Leadership Behaviors of College Physical Education Teachers met the requirements.

Table 4 Internal consistency coefficient $(\mathrm{N}=324)$

\begin{tabular}{lcccc}
\hline scale & $\begin{array}{c}\text { Team } \\
\text { cooperation }\end{array}$ & $\begin{array}{c}\text { System } \\
\text { construction }\end{array}$ & $\begin{array}{c}\text { Professional } \\
\text { development }\end{array}$ & $\begin{array}{c}\text { Total } \\
\text { questionnaire }\end{array}$ \\
\hline$a$ coefficient & 0.950 & 0.936 & 0.934 & 0.945 \\
\hline
\end{tabular}

validity analysis. Content validity test. According to table 5, the correlation coefficients of each factor were higher than that of total questionnaire, and the correlations between each factors were low. It can be concluded that Questionnaire of Leadership Behaviors of College Physical Education 
Teachers had high content validity.

Table 5 correlation coefficient matrix $(\mathrm{N}=324)$

\begin{tabular}{lcccc}
\hline & $\begin{array}{c}\text { Team } \\
\text { cooperation }\end{array}$ & $\begin{array}{c}\text { System } \\
\text { construction }\end{array}$ & $\begin{array}{c}\text { Professional } \\
\text { development }\end{array}$ & $\begin{array}{c}\text { Total } \\
\text { questionnaire }\end{array}$ \\
\hline $\begin{array}{l}\text { Team cooperation } \\
\text { System } \\
\text { construction } \\
\begin{array}{c}\text { Professional } \\
\text { development }\end{array}\end{array}$ & $0.493^{* *}$ & 1 & & \\
Total questionnaire & $0.518^{* *}$ & $0.395^{*}$ & 1 & \\
\hline
\end{tabular}

Construct validity test. Using the software LISREL8.7, taking 18 factors as observation variables, and 3 factors as latent variables, the confirmatory factor analysis was conducted to investigate the structural validity of the questionnaire. The path diagram of confirmatory factor analysis can be seen in Figure 1. The fitting index can be seen in table 5.

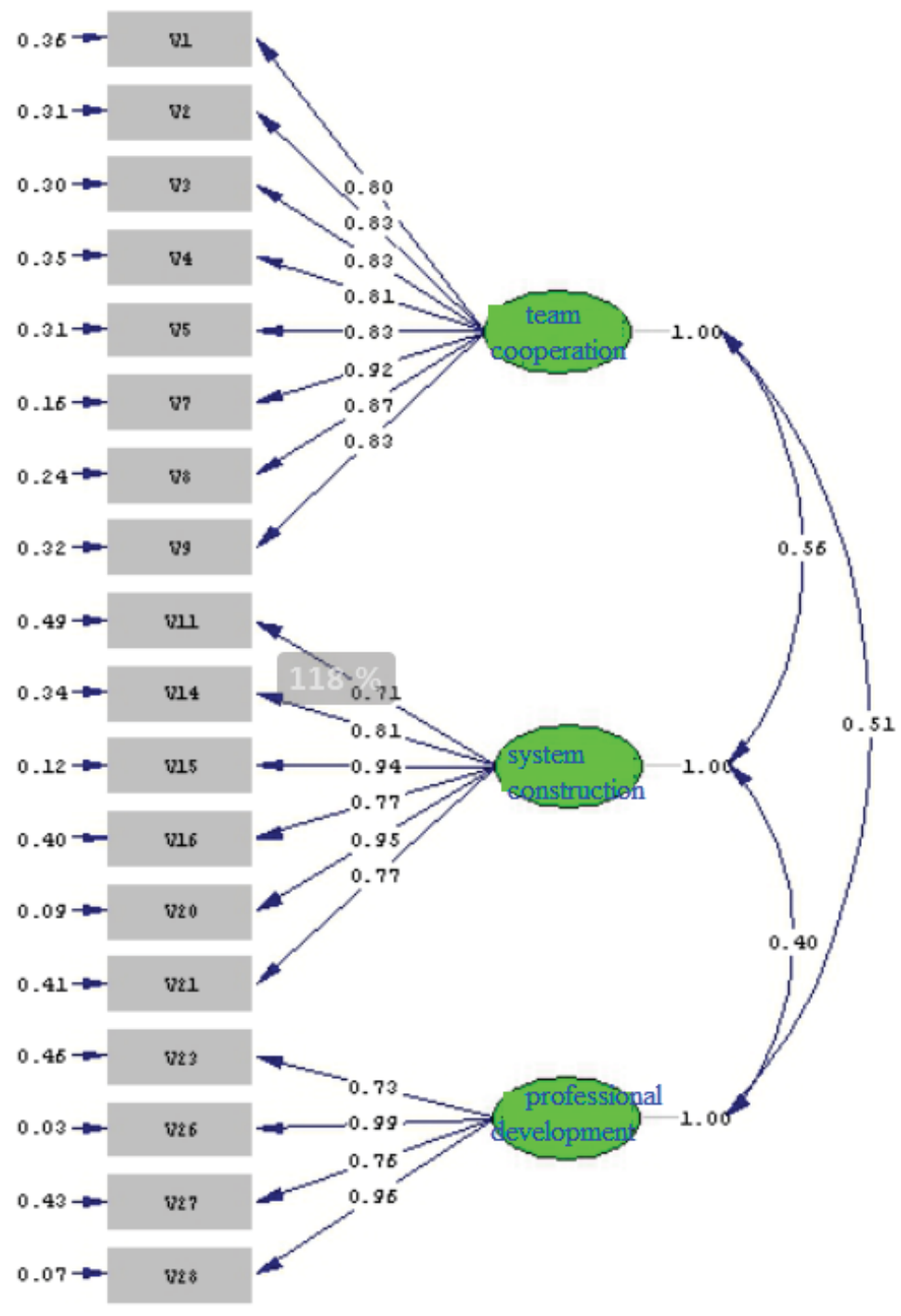

Chi-3 quare $=328.28, d f=172, P-v a l$ ue $=0.00000$, RMrSA $=0.073$

Figure 1. The path diagram of confirmatory factors in Questionnaire of Leadership Behaviors of College Physical Education Teachers 
Table 6 Fitting index of each item in confirmatory factor analysis $(\mathrm{N}=324)$

\begin{tabular}{llllllllll}
\hline Fitting index & $\chi^{2}$ & $d f$ & $P$ & $\chi^{2} / d f$ & $N F I$ & NNFI & IFI & CFI & RMSEA \\
\hline Structure model & 328.28 & 172 & $<0.0001$ & 1.909 & 0.91 & 0.93 & 0.94 & 0.94 & 0.073 \\
\hline
\end{tabular}

It can be seen in Figure 1, the factor loadings of principal components of the 18 items were greater than 0.40 . From table 6 it can be seen, the fitting indexes of structural equation model, $\chi^{2} / d f 、 N F I 、 N N F I 、 I F I$ and $C F I$ were $1.909,0.91,0.93,0.94$ and $0.94, R M S E A=0.073$. The structure model had good fitting degree, which means Questionnaire of Leadership Behaviors of College Physical Education Teachers has good structural validity.

Variationanalysis of college physical education teachers' leadership behaviors. Results of $\mathrm{T}$ test and ANOVA showed that the differences on educational degree, professional titles and ages had great influence on college physical education teachers' leadership behaviors, while gender did not have significant effects.(shown in Table 7).

Table 7 Analysis of differences in physical education teachers'

leadership behaviors $(\mathrm{N}=324)$

\begin{tabular}{cllll}
\hline Category & level & $\begin{array}{l}\text { Team } \\
\text { cooperation }\end{array}$ & $\begin{array}{l}\text { System } \\
\text { construction }\end{array}$ & $\begin{array}{l}\text { Professional } \\
\text { development }\end{array}$ \\
\hline \multirow{2}{*}{ gender } & male & $28.02 \pm 3.25$ & $19.23 \pm 4.18$ & $14.78 \pm 3.87$ \\
& female & $27.52 \pm 2.68$ & $18.65 \pm 3.54$ & $15.27 \pm 3.35$ \\
\hline \multirow{2}{*}{$\begin{array}{c}\text { Education } \\
\text { degree }\end{array}$} & Undergraduate & $25.86 \pm 2.91^{* *}$ & $22.84 \pm 2.64^{* *}$ & $13.21 \pm 4.05$ \\
& master & $28.81 \pm 3.22^{* *}$ & $24.02 \pm 3.45^{*}$ & $15.54 \pm 3.26^{* *}$ \\
title & doctor & $34.44 \pm 3.82^{* *}$ & $25.11 \pm 2.84^{*}$ & $18.65 \pm 2.65^{* *}$ \\
\hline \multirow{2}{*}{ age } & Lecturer and below & $24.56 \pm 3.14^{* *}$ & $19.48 \pm 3.82^{* *}$ & $14.35 \pm 2.73^{* *}$ \\
& lecturer & $27.64 \pm 2.95^{* *}$ & $21.64 \pm 2.65^{* *}$ & $16.81 \pm 3.55^{* *}$ \\
& (associate) professor & $31.36 \pm 3.44^{* *}$ & $24.71 \pm 4.17^{* *}$ & $18.34 \pm 3.26^{* *}$ \\
\hline & 29 years old or & $24.65 \pm 3.12$ & $19.14 \pm 2.85^{* *}$ & $10.31 \pm 2.94^{* *}$ \\
& younger & $24.43 \pm 3.25$ & $21.23 \pm 3.65^{* *}$ & $12.29 \pm 3.82^{* *}$ \\
& $30-39$ years old & $24.58 \pm 4.18$ & $23.45 \pm 3.19^{* *}$ & $13.97 \pm 2.98^{* *}$ \\
\hline & $40-49$ years old & $25.01 \pm 2.88$ & $25.54 \pm 3.78^{* *}$ & $16.22 \pm 3.47^{* *}$ \\
\hline
\end{tabular}

note: * represent $\mathrm{P}<0.05, * *$ represent $\mathrm{P}<0.01$

As it can be seen from table 7, there was no significant difference in the leadership behavior of college physical education teachers with different genders $(\mathrm{P}>0.05)$, but the influences of educational degrees, professional titles and ages were great, and showing an increasing trend. The single factor variance analysis showed that, except for the factor of age, which did not have significant impact on team cooperation $(\mathrm{P}>0.05)$, all factors had significant differences $(\mathrm{P}<0.05)$ on each dimension. By group comparisons, master and doctor teachers have significant difference only on the dimension of system construction $(\mathrm{P}<0.05)$; the differences of other groups were not significant $(\mathrm{P}<0.01)$. 


\section{Conclusions and Suggestions}

Firstly, through revising and improving the Initial Version of Questionnaire of Leadership Behaviors of College Physical Education Teachers, the formal Questionnaire of Leadership Behaviors of College Physical Education Teachers was established. The questionnaire contains 3 dimensions (team cooperation, system construction and professional development) and 18 items. The reliability results showed that the a coefficients of each dimension were $0.950,0.936$ and 0.934, respectively. The coefficient of the questionnaire was 0.945. By establishing structural equation model, fitting indexes $\chi^{2} / d f 、 N F I 、 N N F I$ 、IFI and CFI were obtained as 1.909, 0.91, 0.93, 0.94 and $0.94, R M S E A<0.08$, which means the structural model was of great significance $(<0.0001)$. Thus, the reliability and validity of Questionnaire of Leadership Behaviors of College Physical Education Teacher were high.

Secondly, from $t$ test and ANOVA of the survey data, it can be found that there was no significant difference in the leadership behavior of college physical education teachers with different genders $(\mathrm{P}>0.05)$, but the influences of educational degrees, professional titles and ages were great, and showing an increasing trend. The single factor variance analysis showed that, except for the factor of age, which did not have significant impact on team cooperation $(\mathrm{P}>0.05)$, all factors had significant differences $(\mathrm{P}<0.05)$ on each dimension. By group comparisons, master and doctor teachers have significant difference only on the dimension of system construction $(\mathrm{P}<0.05)$; the differences of other groups were not significant $(\mathrm{P}<0.01)$.

Thirdly, the preliminary development of Questionnaire of Leadership Behaviors of College Physical Education Teacher met the basic requirements of psychometric tests. Results showed that the questionnaire had high retest reliability, internal consistency reliability and structure validity, and good reliability, stability and accuracy. It can be used for monitoring and evaluating leadership behavior of college PE teachers, and providing a theoretical reference to the research of leadership behavior of college PE teachers.

\section{References}

[1] J.S. Jin, On teacher leadership, J. Journal of Northwest Normal University (Social Science Edition). 44 (2007) 42-46.

[2] J. Zhao, L. Xie, Jinping Xi's Three Firm Establishment set targets for teachers [ER/OL]. http://cpc.people.com.cn/n/2013/0910/c241220-22871316.html, 2013.09.10

[3] J.S. Jin, Investigation of teacher leadership practice and motivation, J. Research in Education Development. 10 (2008) 33-36.

[4] J.P. Zhou, The connotation and implementation strategy of teachers' leading roles, J. Journal of The Chinese Society of Education. 7 (2009) 27-30.

[5] D. Frost, Teacher Leadership: towards a research agenda, J. Cambridge Journal of Education. 11 (2003)479- 498.

[6] A.W. Hart, Reconceiving school leadership: Emergent views, J. Elementary School Journal. 96 (1995)

[7] K. Leithwood, D.L. Duke, A centuryps quest to understand school leadership, In: K. S. Louis, J. Murphy ( Eds ) Hand Book of Research on Educational Administration, 2nd edition, Jossey-Bass, San Francisco, 1999, pp. 45

[8] A. Harris, D. Muijs, Teacher leadership and School Development. L. Xu, H.W. Wu, trans. 
Beijing Normal University Publishing House, Beijing, 2007:17.

[9] P. H. Fhelps, Helping teacher become leaders, J. Clearing House: A Journal of Education Strategies, Issues and Ideas. 81(2008) 119-122.

[10] N.G. Lu, Z. Chen, Teacher leadership as reform strategy -- western experience and inspiration from organizational level, J. Research in Education Development. 23 (2006) 54-57

[11] J.W. Long, P. Chen, Current dilemma and prospect of the research on teacher leadership, J. Journal of South China Normal University (Social Science Edition). 2 (2010) 42-45.

[12] A.J. Du, Reflection of teacher leadership in physical education, J. Journal of Shanghai University of Sport. 6 (2003) 118-120.

[13] B. Kadir, A. Battal, Teacher Leadership Scale: A Validity and Reliability Study, J. A Journal of Elementary Education. 9 (2010) 764-775.

[14] R. Rodriguez, Leadership Behavior Description Questionnaire. Online Instruments, Data Collection, and Electronic Measurements: Organizational Advancements, 2013, 97-117. 